\title{
Erratum
}

Pneumologe $2020 \cdot 17: 36$

https://doi.org/10.1007/s10405-019-00288-3

Online publiziert: 11. November 2019

(c) Springer Medizin Verlag $\mathrm{GmbH}$, ein Teil von Springer Nature 2019
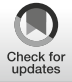

\section{S. Eisenmann}

Abteilung Pneumologie, Klinik für Innere Medizin I, Martin-Luther-Universität Halle-Wittenberg, Halle, Deutschland

\section{Erratum zu: Endobronchialer Ultraschall - Bewährtes und Neues}

\section{Erratum zu:}

Der Pneumologe 2019

https://doi.org/10.1007/s10405-01900282-9

In $\bullet$ Abb. 4b (Ultraschallbild) wurde der Pfeil, der den beschriebenen Embolus der Unterlappenarterie kennzeichnen sollte, falsch positioniert. Wir bitten, dieses Versehen $\mathrm{zu}$ entschuldigen und die im folgenden Bild richtige Kennzeichnung zu beachten:

\section{Korrespondenzadresse}

Dr. S. Eisenmann

Abteilung Pneumologie, Klinik für Innere Medizin I, Martin-Luther-Universität HalleWittenberg

Ernst-Grube-Straße 40, 06120 Halle,

Deutschland

stephan.eisenmann@uk-halle.de
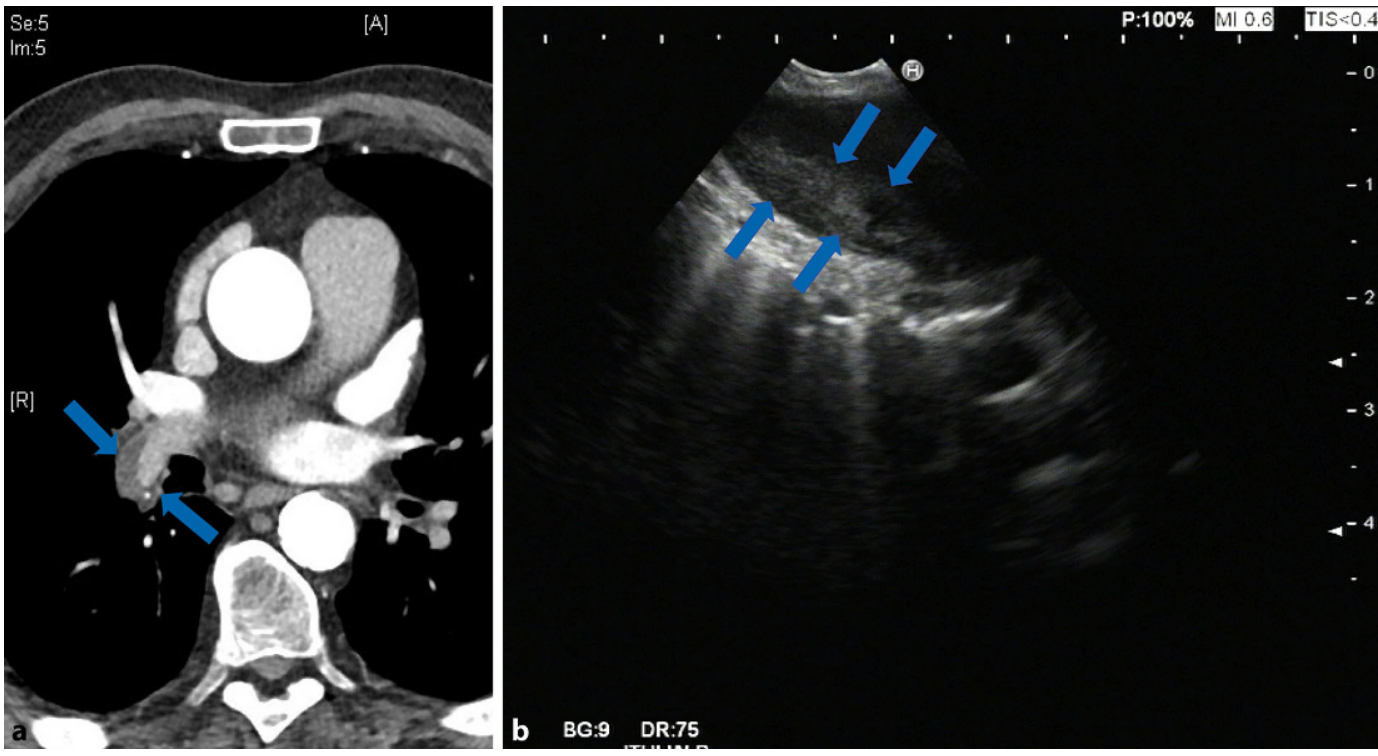

Abb. $4 \triangleleft$ Gefäßwandständiger Embolus in der Unterlappenarterie rechts (jeweils durch Pfeile markiert) in der Computertomogra-

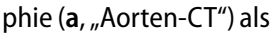
Lymphknoten beschrieben, im endoskopischen Ultraschall-Bild als echoreiche intravaskuläre Raumforderung erkennbar (b)

Die Online-Version des Originalartikels ist unter https://doi.org/10.1007/s10405-019-00282-9 zu finden. 